\title{
Discapacidad y consentimiento informado en el ámbito sanitario y bioinvestigador
}

\section{Disability and informed consent in the health field and bio researcher}

Inmaculada Vivas Tesón*

\section{Resumen}

El carácter preceptivo y vinculante de la Convención ONU sobre los Derechos de las Personas con Discapacidad hecha en Nueva York el 13 de diciembre de 2006 (y su Protocolo Facultativo) obliga a los países que ratifiquen la Convención a adaptar sus legislaciones nacionales a los principios, valores y mandatos proclamados en dicho Tratado internacional. En concreto, su artículo 12 obliga a dejar atrás el modelo basado en la sustitución en la toma de decisiones para adoptar un modelo basado en la asistencia en la toma de decisiones. En dicho modelo ha de encajar, sin duda, la regulación del consentimiento informado de la persona con discapacidad en materia de tratamientos sanitarios y de bioinvestigación.

Palabras clave: Personas frágiles. Convención ONU sobre los Derechos de las Personas con Discapacidad. Dignidad. Consentimiento informado. Biobancos. Investigación biomédica.

\section{Abstract}

The mandatory and binding nature of the UN Convention on the Rights of Persons with Disabilities, adopted in New York on the $13^{\text {th }}$ of December 2006, (and its optional protocol) obliges countries which ratify the Convention to adapt their national legislations to the principles, values and mandates proclaimed in this international Agreement. In particular, article 12 requires a change from the model of decision-making based on substitution to one based on support. Undoubtedly, the regulation of informed consent from persons with disabilities in the context of medical treatment and bioresearch must fit into this model.

Keywords: Vulnerable persons. UN Convention on the Rights of Persons with Disabilities. Dignity. Informed consent. Biobanks. Biomedical research.

Doutora em Direito Civil. Profesora titular de Derecho civil da Universidade de Sevilha. Sevilha Andaluzia - Espanha. Email: ivivas@us.es 


\section{Discapacidad y consentimiento informado en el ámbito sanitario}

Un nuevo enfoque a partir de la Convención ONU sobre los derechos de las personas con discapacidad

El primer Tratado de derechos humanos del Siglo XXI, la Convención ONU sobre los derechos de las personas con discapacidad, hecha en Nueva York en el año 2006 (en adelante, CDPD), cuyos principios cardinales son "in dubio pro capacitas" e "intervención mínima", contempla un cambio en el modelo a adoptar a la hora de regular la capacidad jurídica de las personas con discapacidad, especialmente, en aquellas situaciones en las cuales puede resultar necesario algún tipo de intervención de terceros: mientras que el sistema tradicional tiende hacia un modelo de "sustitución" en la toma de decisiones, el modelo de derechos humanos basado en la dignidad intrínseca de todas las personas, sobre el cual gira la Convención, aboga por un modelo de "apoyo" en la toma de decisiones.

La CDPD hace hincapié en la enorme importancia que reviste para las personas con discapacidad el respeto a su autonomía individual, incluida la libertad de tomar decisiones, su voluntad, sus preferencias (Preámbulo, letra $\mathrm{n}$ y arts. 3 y 12.4).

Al respecto, permítasenos subrayar que la especial trascendencia de dicho Tratado Internacional no radica en su contenido innovador, que no lo es, sino en que, a diferencia de otras Declaraciones de derechos y principios generales de la ONU (como la Declaración de los Derechos del Retrasado Mental y la Declaración de los derechos de los Impedidos o las Normas Uniformes para la Igualdad de Oportunidades y la no Discriminación), inspiradoras de leyes y políticas de muchos países pero carentes de fuerza normativa, la CDPD es un instrumento jurídico de carácter obligatorio. No estamos, pues, ante una mera declaración o recomendación, sino ante un pacto internacional preceptivo y vinculante, lo que está obligando a proceder a una íntegra revisión legislativa que logre que nuestro Derecho interno se corresponda, exactamente, 
con los principios, valores y mandatos proclamados en dicho Tratado internacional, debiendo, por consiguiente, revisar y adaptar nuestra legislación al reconocimiento y garantía de los derechos de las personas con discapacidad, muy especialmente, el de igualdad.

Actualmente, estamos inmersos en dicho proceso de reformulación $y$, en su caso, supresión de normas vigentes discriminatorias. Ejemplo de ello lo son la Ley 26/2011, de 1 de agosto, el Real Decreto 1276/2011, de 16 de septiembre, de adaptación normativa a la Convención Internacional sobre los Derechos de las Personas con Discapacidad y el y el reciente Real Decreto-Legislativo 1/2013, de 29 de noviembre, por el que se aprueba el Texto Refundido de la Ley General de Derechos de las Personas con Discapacidad y de su inclusión social (el título de la norma es indudablemente equívoco, pues no se trata una Ley General de Discapacidad sino de una mera refundición de tres leyes en un único texto: la LISMI, la LIONDAU y la LISMID).

Dicho proceso de adaptación de nuestro Ordenamiento Jurídico a la CDPD está aún inacabado. Estamos a la espera de una anunciada reforma del procedimiento de incapacitación judicial ${ }^{1}$, de la que tan sólo

\footnotetext{
Al respecto, es preciso recordar que la Ley $1 / 2009$, de 25 de marzo, de reforma de la Ley de 8 de junio de 1957, sobre el Registro Civil, en materia de incapacitaciones, cargos tutelares y administradores de patrimonios protegidos, y de la Ley 41/2003, de 18 de noviembre, sobre protección patrimonial de las personas con discapacidad y de modificación del Código Civil, de la Ley de Enjuiciamiento Civil y de la normativa tributaria con esta finalidad, establece, en su Disposición final $1^{\text {a }}$, que "el Gobierno, en el plazo de seis meses desde la entrada en vigor de esta Ley-, remitirá a las Cortes Generales un Proyecto de Ley de reforma de la legislación reguladora de los procedimientos de incapacitación judicial, que pasarán a denominarse procedimientos de modificación de la capacidad de obrar, para su adaptación a las previsiones de la Convención Internacional sobre los Derechos de las Personas con Discapacidad, adoptada por Naciones Unidas el 13 de diciembre de 2006", promesa incumplida. Por su parte, la Ley 26/2011, de 1 de agosto, de adaptación normativa a la Convención Internacional sobre los Derechos de las Personas con Discapacidad, en su Disposición adicional $7^{a}$, rubricada "Adaptación normativa relativa al ejercicio de la capacidad jurídica por las personas con discapacidad, en igualdad de condiciones", contempla que "el Gobierno, en el plazo de un año a partir de la entrada en vigor de esta Ley, remitirá a las Cortes Generales un proyecto de ley de adaptación normativa del ordenamiento jurídico para dar cumplimiento al artículo 12 de la Convención Internacional sobre los Derechos de las Personas con Discapacidad, en lo relativo al ejercicio de la capacidad jurídica por las personas con discapacidad, en igualdad de condiciones que las demás en todos los aspectos de la vida. Dicho proyecto de ley establecerá las modificaciones necesarias en el proceso judicial de determinación de apoyos para la toma libre de decisiones de las personas con discapacidad que los precisen", compromiso, asimismo, incumplido.
} 
es conocida su denominación, "procedimiento de modificación de la capacidad de obrar" y de la creación de mecanismos de protección de la persona ajustados al modelo social de discapacidad proclamado por la CDPD, los cuales, por su elasticidad y flexibilidad, han de poderse amoldar a todas y cada una de las situaciones de debilidad de una persona, intentando brindarle el apoyo más adecuado a su concreta necesidad y dando siempre espacio al desarrollo de su personalidad, lo que obliga a considerar a la tutela como remedio tuitivo extremo y a proteger a la persona desde una óptica humana y no, exclusivamente, patrimonial.

Sólo ha de importar la persona, su personalidad, su voluntad, sus valores universales de dignidad humana, libertad, igualdad, solidaridad y participación. Nuestras leyes han de impregnarse, pues, del principio personalista, conforme al cual el rol de los derechos fundamentales es estratégico, de primera importancia.

En pocas palabras, la CDPD viene a decirnos que dejemos de una vez de adueñarnos de la vida de las personas con discapacidad y de tomar decisiones por su nombre y cuenta. Satisfacer sus necesidades vitales, conocer sus sentimientos, lograr su bienestar (no sólo económico, sino físico y espiritual), promover su autoestima y, en definitiva, alcanzar su felicidad, poco o nada tiene que ver con su mayor o menor capacidad de entender y querer, sino con su condición de ser humano y, por consiguiente, con el máximo respeto a su yo.

No se trata más que de respetar sus derechos, entendidos éstos no sólo desde el plano jurídico, sino lato sensu: el derecho a la salud, al ocio, a sus inquietudes culturales, a una vida independiente, a la libertad de elegir y de manifestar su consentimiento o disenso (p. ej. en relación a tratamientos médicos u odontológicos, la cesión de sus datos personales, el uso de su imagen, etc.). De este modo, se persigue que la persona sea la única dueña de su propia vida.

Por consiguiente, la obtención del consentimiento informado (en adelante, $\mathrm{Cl}$ ) de la persona con discapacidad en materia de 
tratamientos sanitarios debe estar presidida por el derecho del paciente a su autodeterminación y, por consiguiente, pese a tratarse de un sujeto vulnerable, es preciso contar con su propia voluntad y no (tan sólo, con carácter muy excepcional cuando sea estrictamente necesario) con la de sus familiares o representantes legales.

Por puras razones de comodidad práctica, ya sea por sus parientes y allegados, ya por los jueces, ya por los profesionales sanitarios, partimos ex ante de que la persona frágil no puede dar su $\mathrm{Cl}$, de modo que prescindimos de ella a la hora de participar en la elección de un tratamiento sanitario para su mente y/o su cuerpo, sustituyéndola en su vida y en su libertad personal. Sin embargo, por comodidad, automatismo o mecanicidad a la hora de realizar actos en el ámbito de la salud no pueden dejar de respetarse y tutelarse los derechos fundamentales (los cuales, recordemos, son inviolables) de la persona frágil, que no es, por su situación de vulnerabilidad, un sujeto pasivo al que podamos expropiarle (sin justiprecio alguno) su vida.

Sin duda, se requiere una línea estratégica de formación específica y colaboración activa por parte de todos (en particular, familiares, jueces y operadores sanitarios) en dar el mayor espacio vital posible a la persona con discapacidad en relación a los deseos y preferencias en el ámbito sanitario.

A diferencia de España, en el Derecho italiano, la institución tuitiva de la "amministrazione di sostegno" (la cual podría traducirse como "administración de apoyo"), introducida en el Codice civile (en concreto, en sus arts. 404 a 413) por la Ley de 6 de enero de 2004 y dirigida a tutelar a la persona más que a su patrimonio, se encuentra en perfecta sintonía con el espíritu de la CDPD (debiéndose subrayar, que la reforma se adelantó al citado Tratado Internacional, puesto que Italia lo ratificó mediante la Ley 18/2009, de 3 de marzo), destacadamente, con el reconocimiento que en su Preámbulo, letra $n$ ) hace a "la importancia que para las personas con discapacidad reviste su autonomía e 
independencia individual, incluida la libertad de tomar sus propias decisiones"2.

Preciso es señalar que la Ley 25/2010, de 29 de julio, del Libro Segundo del Código civil de Cataluña, relativo a la persona y la familia, contempla, junto con las tradicionales instituciones de protección de la persona incapacitada (tutela, curatela y defensor judicial) y siguiendo las directrices de la CDPD, un nuevo régimen, la asistencia (arts. 226-1 a 226-7).

\subsection{El consentimiento (o disenso) informado como derecho fundamental}

El art. 5 del Convenio para la protección de los Derechos Humanos y la Dignidad del Ser Humano con respecto a las aplicaciones de la Biología y la Medicina de 1997, más conocido como "Convenio de Oviedo", instrumento internacional de carácter vinculante para los países que lo suscriben, como es el caso de España, dispone:

Artículo 5. Regla general.

Una intervención en el ámbito de la sanidad sólo podrá efectuarse después de que la persona afectada haya dado su libre e informado consentimiento.

Dicha persona deberá recibir previamente una información adecuada acerca de la finalidad y la naturaleza de la intervención, así como sobre sus riesgos y consecuencias.

En cualquier momento la persona afectada podrá retirar libremente su consentimiento.

Y en su art. 10 establece:

Artículo 10) Vida privada y derecho a la información.

1. Toda persona tendrá derecho a que se respete su vida privada cuando se trate de informaciones relativas a su salud.

2 Para un mayor estudio, pueden consultarse nuestros trabajos Más allá de la capacidad de entender y querer. Un análisis de la figura italiana de la administración de apoyo y una propuesta de reforma del sistema tuitivo español. (2012) y Una propuesta de reforma del sistema tuitivo español: proteger sin incapacitar (2012). 
2. Toda persona tendrá derecho a conocer toda información obtenida respecto a su salud. No obstante, deberá respetarse la voluntad de una persona a no ser informada.

Por su parte, el art. 3 , en su apartado $2^{\circ}$, letra a), de la Carta de derechos fundamentales de la Unión Europea (NIZA, 2000), dispone:

Artículo 3. Derecho a la integridad de la persona.

1. Toda persona tiene derecho a su integridad física y psíquica.

2. En el marco de la medicina y la biología se respetarán en particular:

el consentimiento libre e informado de la persona de que se trate, de acuerdo con las modalidades establecidas por la Ley $[\ldots]$.

Así las cosas, el $\mathrm{Cl}$ es un acto volitivo requerido en distintas actuaciones en el ámbito de la salud, tales como en un ingreso hospitalario, una intervención quirúrgica, una extracción de una muestra de orina o sangre, en una transfusión de sangre, en la práctica de una biopsia, en la extracción y trasplante de órganos o en la participación en ensayos clínicos.

Como señala el Tribunal Supremo en su Sentencia de 12 de enero de 2001,

la iluminación y el esclarecimiento, a través de la información del médico, para que el enfermo pueda escoger en libertad dentro de las opciones posibles que la ciencia médica le ofrece al respecto e incluso la de no someterse a ningún tratamiento, ni intervención, no supone ningún formalismo sino que encuentra fundamento y apoyo en la misma Constitución española, en la exaltación de la dignidad de la persona que se consagra en su art. 10.1, pero sobre todo en la libertad, de que se ocupa el art. 1.1, reconociendo la autonomía del individuo para elegir entre las diversas opciones vitales que se presenten, de acuerdo con sus propios intereses y preferencias [...]. 
El Tribunal Supremo, con apoyo en diversos textos internacionales de protección de derechos humanos que arrancan de la Declaración Universal de 1948, concluye que

el consentimiento informado constituye un derecho humano fundamental, precisamente una de las últimas aportaciones realizada en la teoría de los derechos humanos, consecuencia necesaria o explicación de los clásicos derechos a la vida, a la integridad física y a la libertad de conciencia. Derecho a la libertad personal, a decidir por sí mismo en lo atinente a la propia persona y a la propia vida y consecuencia de la autodisposición sobre el propio cuerpo.

Este entronque del $\mathrm{Cl}$ con los derechos fundamentales en Derecho Español ha sido recientemente confirmado por el Tribunal Constitucional, en su Sentencia de 28 de marzo de 2011 acerca de la estimación de un recurso de amparo por vulneración de derechos fundamentales, en concreto, el derecho a la tutela judicial efectiva (art. 24.1 CE) y los derechos a la integridad física y a la libertad (arts. 15 y 17.1 CE), en relación a la desestimación de la reclamación de responsabilidad civil derivada de asistencia sanitaria por la pérdida funcional de la mano derecha del paciente tras la realización de un cateterismo cardíaco, sin que se le hubiese informado de los riesgos de la intervención ni se hubiese recabado su consentimiento para la práctica de la misma ${ }^{3}$.

Sin embargo, dicha conexión con los derechos fundamentales de la persona es posiblemente, como se ha señalado ${ }^{4}$, (PARRA LUCAN, 2003) un exceso del que el propio Supremo no ha pretendido sacar ninguna consecuencia concreta, sino sólo evitar una interpretación que reduzca la legalidad a un mero requisito formal cuyo incumplimiento carezca de consecuencias jurídico privadas.

A tenor del art. 3 de la Ley 41/2002, de 14 de noviembre, básica reguladora de la autonomía del paciente y de derechos y obligaciones

Vid. comentario a dicha Sentencia de Díaz Martínez (2011) e Moure González (2011).

PARRA LUCAN, Ma . A.: "La capacidad del paciente para prestar válido consentimiento informado.

El confuso panorama legislativo español”, en Aranzadi Civil-Mercantil, núm. 2, 2003. 
en materia de información y documentación clínica (en adelante, LAP), por $\mathrm{Cl}$ ha de entenderse, a efectos de dicha Ley, "la conformidad libre, voluntaria y consciente de un paciente, manifestada en el pleno uso de sus facultades después de recibir la información adecuada, para que tenga lugar una actuación que afecta a su salud".

Esto significa que toda actuación en el ámbito de la salud de un paciente necesita su consentimiento libre y voluntario, una vez que, recibida la correspondiente información adecuada, haya valorado las opciones propias del caso (art. 8.1 LAP). Así las cosas, los aspectos básicos que caracterizan el $\mathrm{Cl}$ en las actuaciones sanitarias son: La información que ha de proporcionarse al sujeto ha de ser adecuada

- La persona debe tener capacidad para expresar el consentimiento

- Libertad de elección de la persona y ausencia de coerción.Por tanto, sin duda alguna, el consentimiento libre e informado está estrechamente vinculado con la dignidad ${ }^{5}$ y la libertad personal. (PARRA LUCAN, 2003)

Enorme relevancia alcanzan tanto el testamento vital o documento de voluntades anticipadas, como la escritura de autotutela, tal y como se deduce del art. 9 del citado Convenio de Oviedo:

Artículo 9. Deseos expresados anteriormente.

Serán tomados en consideración los deseos expresados anteriormente con respecto a una intervención médica por un paciente que, en el momento de la intervención, no se encuentre en situación de expresar su voluntad.

De este modo, logramos planificar y decidir pro futuro nuestra propia vida evitando, de este modo, que lo hagan terceros por nosotros,

5 Siguiendo a mi maestro, López Y López (2012, p. 39), refiriéndose a la carga de valores generales que se acumulan alrededor del término de persona, "aunque sobre estos valores puede haber discrepancias, en nuestra cultura jurídica todos estamos de acuerdo con el dicho constitucional de que la dignidad de la persona es el valor superior del Derecho (artículo 10 de la Constitución Española). Esa palabra, 'dignidad', indica la tenencia de las cualidades más excelentes y respetables por sí mismas del ser humano, y es tenencia de cualquier persona, con independencia de su condición". 
ante una eventual pérdida de nuestra capacidad de entender y querer, o bien de una situación de coma o de un estado vegetativo permanente, situaciones éstas en las cuales ya nos será imposible manifestar nuestra voluntad. El documento de voluntades anticipadas y la autotutela ${ }^{6}$ se convierten, pues, en herramientas jurídicas de bajo coste económico pero de incalculable valor y vital utilidad.

\section{El consentimiento informado para la obtención, utilización y cesión del material biológico con fines de investigación biomédica}

\subsection{La singularidad del $\mathrm{Cl}$ en el contexto bioinvestigador}

Según la Exposición de Motivos de la Ley 14/2007, de 3 de julio, de Investigación Biomédica (en adelante, LIB) ${ }^{7}$, dicha ley

se construye sobre los principios de la integridad de las personas y la protección de la dignidad e identidad del ser humano en cualquier investigación biomédica que implique intervenciones sobre seres humanos, así como en la realización de análisis genéticos, el tratamiento de datos genéticos de carácter personal y de las muestras biológicas de origen humano que se utilicen en investigación. En este sentido, la Ley establece que la libre autonomía de la persona es el fundamento del que se derivan los derechos específicos a otorgar el consentimiento y a obtener la información previa. Asimismo, se establece el derecho a no ser discriminado, el deber de confidencialidad por parte de cualquier persona que en el ejercicio de sus funciones acceda a información de carácter personal, el principio de gratuidad de las donaciones de material biológico, y fija los estándares de calidad y seguridad, que incluyen la

6 De la tutela hemos tenido ocasión de ocuparnos con cierto detenimiento en nuestro trabajo La dignidad de las personas con discapacidad: logros y retos jurídicos. (2010, p. 115-121).

$7 \quad$ La LIB ha sido parcialmente modificada por la DF $8^{\text {a }}$ de la Ley $14 / 2011$, de 1 de junio, de la Ciencia, la Tecnología y la Innovación. 
trazabilidad de las células y tejidos humanos y la estricta observancia del principio de precaución en las distintas actividades que regula.

Sentado lo anterior, el $\mathrm{Cl}$ para la recogida, almacenamiento y utilización de muestras biológicas con fines de investigación biomédica ${ }^{8}$ presenta características singulares que lo separan del tradicional $\mathrm{Cl}$ del paciente $\mathrm{y}$, por consiguiente, comporta reflexiones jurídicas diferentes $\mathrm{y}$, tal vez, una reformulación del concepto de $\mathrm{Cl}$ en el contexto de la bioinvestigación y, en consecuencia, una disciplina legal ad hoc ${ }^{9}$.

Ante todo, es preciso distinguir dos fases distintas, cada una con problemática diferente respecto de la otra. De un lado, el $\mathrm{Cl}$ es preciso en una primera fase de extracción del material biológico, en cuyo caso el derecho fundamental que resulta tutelado por el consentimiento es la libertad personal o autodeterminación del sujeto en orden a la propia salud; de otro, el Cl a la conservación en biobancos (en adelante, BB) ${ }^{10}$

8 La obtención de muestras biológicas con fines de diagnóstico médico se rige por lo dispuesto en la LAP. Al respecto se pronuncia Romeo Casabona, C. Ma: "Implicaciones jurídicas de la utilización de muestras biológicas humanas y biobancos en investigación científica”, (BILBAO, 2007) (http://www.catedraderechoygenomahumano.es/images/Informe_final_completo.pdf), p. 39 , para quien "no existe ninguna duda acerca de la aplicabilidad de la LAP a los actos de obtención de muestras biológicas con fines diagnósticos".

9 De esta opinión, Picozzi y Ferioli (2011, p.570): "La conservazione del materiale biologico finalizzato alla ricerca scientifica: questioni giuridiche e riflessioni etiche sulle biobanche [...] per le biobanche è necessario un consenso informato diverso da quello classico, in cui possa essere prevista una mediazione etica tra l'autonomia dei donatori, l'integrità morale dei ricercatori e la governance della biobanca".

10 La utilización del término "biobank" es reciente en la literatura científica, surgiendo, a mitad de los años 90, en el artículo de Loft y Poulsen (1996). De Robbio y Corradi (2010, p. 306) apuntan la posibilidad de que el término "biobanco" apareciera en escena con anterioridad, ya en los años 80. La LIB, ofrece la siguiente definición de "biobanco": "Establecimiento público o privado, sin ánimo de lucro, que acoge una colección de muestras biológicas concebida con fines diagnósticos o de investigación biomédica y organizada como una unidad técnica con criterios de calidad, orden y destino". Por su parte, el Real Decreto 1716/2011, de 18 de noviembre, por el que se establecen los requisitos básicos de autorización y funcionamiento de los biobancos con fines de investigación biomédica y del tratamiento de las muestras biológicas de origen humano, y se regula el funcionamiento y organización del Registro Nacional de Biobancos para investigación biomédica (en adelante, RD 2011), el cual acaba de entrar en vigor, proporciona la siguiente definición de Biobanco con fines de investigación biomédica: "establecimiento público o privado, sin ánimo de lucro, que acoge una o varias colecciones de muestras biológicas de origen humano con fines de investigación biomédica, organizadas como una unidad técnica con criterios de calidad, orden y destino, con independencia de que albergue muestras con otras finalidades". 
y a la utilización investigadora de la muestra biológica extraída se dirige a tutelar la identidad e intimidad del sujeto fuente. Tal vez, no debiera hablarse de $\mathrm{Cl}$ en singular sino en plural ${ }^{11}$.

Claro lo anterior, según la LIB, por "consentimiento", a los efectos de dicha Ley, ha de entenderse "manifestación de la voluntad libre y consciente válidamente emitida por una persona capaz, o por su representante autorizado, precedida de la información adecuada" (art. 3.f).

Partiéndose de que la muestra biológica no tiene exclusivamente una dimensión física o material ${ }^{12}$, sino, junto a ésta, una privilegiada dimensión informacional ${ }^{13}$, la singularidad del $\mathrm{Cl}$ para la recogida y utilización de material biológico con fines de investigación biomédica ${ }^{14}$ radica, fundamentalmente, en las ideas siguientes: los datos genéticos presentan un carácter indiscutiblemente personalísimo, constituyendo el patrimonio más profundo y esencial de la persona humana; (INTRONA, 1992, p. 29).

11 Así lo apunta Macilotti (2009, v. 3, p. 158), para quien "si dovrebbe correctamente parlare di consenso al plurale, in quanto i beni giuridici sui quali incide l'espressione di volontà sono molteplici".

12 En relación a ello se plantea cuál es la consideración jurídica y el régimen dominical sobre los materiales biológicos separados del cuerpo humano. Para una interesante exposición de la problemática y las distintas posturas doctrinales, vid. Macilotti, Izzo, Pascuzzi y Barbareschi (2011).

13 En este sentido, Macilotti (2008, p. 158), señala: "Ma la materialità identifica solo una delle possibili dimensioni entro cui vivono le vicente dei tessuti umani. Con lo sviluppo delle conoscenze e delle tecnologie di ricerca in ambito genetico i campioni biologici umani tendono sempre più ad identificare una fonte privilegiata ed insostituibile di dati medici e genetici utili allo sviluppo della scienza medica. Si tratta di dati che offrono informazioni decisive sullo stato di salute, l'identità biologica, la predisposizione a contrarre determinate malattie, la paternità del soggetto al quale appartengono".

14 Como expresa Macilotti (2008, p. 158) "nei campioni biologici convivono dunque due dimensioni che, almeno dal punto di vista giuridico, mostrano di avere caratteristiche profondamente diverse. La dimensione materiale plasmata sul diritto di proprietà e la dimensione informazionale espressione della personalità e dell'identità del soggetto. A maggior ragione tale duplicità sussiste se si considera che le informazioni sopravvivono anche quando i campioni biologici dai quali sono ricavate siano interamente consumati". 
1. Ios datos biosanitarios, en cuanto datos específicos relacionados con la salud ${ }^{15}$, pertenecen a la categoría de "datos sensibles"16, esto es, aquéllos en relación con los cuales el interesado es más vulnerable cuando son conocidos o utilizados por terceros, con mayor motivo cuando son objeto de acceso, utilización o cesión ilícitas. Como consecuencia de ello, tales datos han de gozar de una protección jurídica más intensa ${ }^{17}$; (ROMEO CASABONA, 2007, p. 21).

2. la información genética que alberga la muestra va más allá del ámbito individual del sujeto fuente de la misma, pudiendo involucrar al grupo familiar, comunidad o población a la que aquél pertenece, pudiendo beneficiarse de los resultados obtenidos con la investigación llevada a cabo con la muestra donada ${ }^{18}$

15 En opinión de Macilotti, Izzo, Pascuzzi y Barbareschi (2008, p. 97): "La disciplina giuridica delle biobanche [...] tali dati consentono di acquisire informazioni relative allo stato di salute, alle caractteristiche biologiche, al grado di predisposizione a contrarre determinate malattie, alla reale paternità e forse, in futuro, anche le qualità dominanti del carattere dei 'donatori".

16 Como expone Rebollo Delgado, L. (2008, p. 178), "los datos sensibles pueden concretarse desde un punto de vista material y desde un punto de vista formal. Materialmente los datos sensibles son aquellos que hacen referencia a cualidades de la persona relacionadas con su dignidad, con aspectos que afectan a su personalidad, que dibujan su forma de ser y de comportarse. Formalmente los datos sensibles son aquellos que requieren unas especiales y reforzadas garantías de uso que alcanzan a su recogida y tratamiento y que sopesan, en estas fases concretas de la protección de datos, especialmente la voluntad de la persona". En la p. 181 el autor afirma que los datos biosanitarios gozan del carácter de datos sensibles, añadiendo que "la protección de datos biosanitarios se constituye en el derecho que todo ser humano tiene de controlar sus datos biológicos, ya tengan éstos aplicaciones médicas o no, y a que su uso no sea contrario a la dignidad del ser humano". Para Villani (2010, p.141) son datos particularmente sensibles "inserite nel 'nucleo duro' della privacy".

17 Díaz Martínez (2007), "no ha de olvidarse, en efecto, que en las investigaciones con material biológico procedente de seres humanos - cualquiera que sea la denominación que en términos jurídicos se le dé, considérese como cosa o no- - aquél es soporte de datos genéticos, lo que exige la sólida protección de algunos derechos fundamentales como la intimidad o el que ha denominado recientemente el Tribunal Constitucional (STC 292/2000, de 30 de noviembre) derecho a la protección de datos, que no comprende sólo los íntimos de la persona, sino cualquier tipo de dato personal, sea o no de aquel carácter".

18 En relación al alcance de los datos genéticos asociados al material biológico humano, el art. 4 de la Declaración Internacional sobre los Datos Genéticos Humanos de 16 de octubre de 2003 dispone:

"a) Los datos genéticos humanos son singulares porque:

i) pueden indicar predisposiciones genéticas de los individuos;

ii) pueden tener para la familia, comprendida la descendencia, y a veces para todo el grupo al que pertenezca la persona en cuestión, consecuencias importantes que se perpetúen durante generaciones;

iii) pueden contener información cuya relevancia no se conozca necesariamente en el momento de extraer las muestras biológicas;

iv) pueden ser importantes desde el punto de vista cultural para las personas o los grupos.

b) Se debería prestar la debida atención al carácter sensible de los datos genéticos humanos e instituir un nivel de protección adecuado de esos datos y de las muestras biológicas". 
3. dado que pueden surgir fines de investigación biomédica imprevisibles o no hipotizables al momento de la obtención de la muestra biológica ${ }^{19}$, resulta imposible informar de la futura utilización de aquélla al sujeto fuente, y ello, sencillamente, porque la Ciencia médica está en continua evolución ${ }^{20} \mathrm{y}$, además, son desconocidos los investigadores o equipos investigadores (españoles o extranjeros ${ }^{21}$ ) que podrán hacer uso del material biológico humano a quienes éste sea cedido ${ }^{22}$, (AZZINI, 2012, p. 117-150) a lo que ha de añadirse la dificultad (o, incluso, imposibilidad, en caso de fallecimiento) práctica que conlleva la necesidad de recontactar, posteriormente, con el sujeto fuente. (MACILOTTI; IZZO; PASCUZZI; BARBARESCHI, 2011, p. 97). Se trata, pues, de un consentimiento a una operación compleja e hipotética, en la que no resulta posible informar pormenorizadamente ex ante al sujeto fuente de los futuros beneficios, riesgos y usos de los datos asociados a su material biológico (lo que le separa del Cl tradicional, en el que la información debe ser precisa y detallada al momento de su prestación), el cual cuenta con un valor potencial de suma importancia para la investigación científica ${ }^{23}$.

19 En este sentido, señala Macilotti (2008, p. 160): "Solo in rarissimi casi al momento della prestazione del consenso il soggetto coinvolto può essere informato puntualmente sulle analisi che saranno condotte sul materiale biologico prelevato dal suo corpo. Molte di queste indagini non sono prevedibili e dipendono dallo sviluppo delle conoscenze scientifiche, altre vengono pianificate solo in momenti successivi".

20 Para Clayton (2005, p. 19), el Cl puede definirse como "one part of honoring the contribution that the person is making to the advancement of knowledge".

21 Al respecto, vid. el RD 65/2006, de 30 de enero, por el que se establecen requisitos para la importación y exportación de muestras biológicas.

22 Como señalan Casado De La Rocha y Etxebarría Agiriano (2008, p. 252), los biobancos "son un recurso que está esencialmente abierto a muchos fines de investigación, y la pregunta entonces es obvia: ¿cómo informar de esos fines aún desconocidos?".

23 En este sentido, Allen e Mcnamara (2009, p. 3): "participants cannot make a real judgment about the benefits or risks when they are asked to give their consent to contribute to a prospective biobank. A meaningful evaluation could only be made if they were provided with information and asked for consent each time their samples or information were used. Researchers argue, however, that obtaining consent for each new use is impractical and that the burden of compliance is prohibitively expensive. Attempts to recontact all participants are likely to be unsuccessful since some will have died or have lost capacity to consent. Others may simply not bother to respond. Continuous requests for further consent may be resented or perceived as burdensome. Reduced participation may be an insurmountable obstacle for some projects, and undermine the validity of others". 
De acuerdo con lo expuesto, el tratamiento jurídico del $\mathrm{Cl}$ para la recogida y utilización de material biológico de origen humano destinado a la investigación biomédica ha de girar en torno a la búsqueda del perfecto equilibrio entre el respeto a la libertad, autodeterminación individual de la persona en orden a la propia salud e intimidad, el interés de la colectividad y las exigencias del progreso científico ${ }^{24}$, tarea ésta nada fácil.

Dentro del nuevo escenario jurídico (sin duda, también, ético y científico, en los cuales no osamos entrar) creado por los avances en la bioinvestigación sobre muestras de origen humano y su tratamiento específico en los BB, son muchas las cuestiones de interés que rodean al $\mathrm{Cl}$ (contenido, forma, responsabilidad médica por ausencia de información, etc.), si bien, por cuanto ahora nos ocupa, nos limitamos a abordar el $\mathrm{Cl}$ procedente de personas mayores de edad con discapacidad, con capacidad judicialmente modificada o no, así como a conocer su participación en todo el proceso de obtención y destino científico de sus muestras biológicas ${ }^{25}$.

Y ello porque las personas con limitada capacidad de autogobierno y decisión son especialmente vulnerables, de ahí que los derechos a la identidad, integridad y dignidad de los que son titulares (al igual que los restantes ciudadanos, lo cual, con frecuencia, se pasa por

24 Para Gómez Sánchez (2008, p. 271), "la articulación jurídica de los diferentes derechos y bienes constitucionalmente protegidos no se plantea tanto en términos de exclusión sino de ponderación y equilibrio entre ellos; es en esta ponderación donde el bienestar del ser humano podría llegar a prevalecer sobre otros intereses sociales o científicos. Jurídicamente este principio de primacía se manifiesta como un límite al derecho fundamental de investigación biomédica de manera que resultarían justificadas las limitaciones que pudieran establecerse para garantizar este principio sin llegar a desnaturalizar el derecho a la investigación o hacerlo impracticable".

25 Como señala Casado De La Rocha (2010, p.3) haciendo referencia a la LIB, "el punto de partida es la sospecha de que, al haber en esta ley tantas excepciones a las exigencias tradicionales del $\mathrm{Cl}$, existe cierto riesgo de caer en una pendiente resbaladiza en la que garantías éticas tradicionales como el requisito del $\mathrm{Cl}$ acaben por desaparecer. Para evitar esto es necesario contar con un concepto más completo de la autonomía de los pacientes y los sujetos de investigación, un concepto donde no se reduzca el respeto de la autonomía a 'cumplir con el expediente' del $\mathrm{Cl}$ en un momento puntual de la investigación”. Y añade: “... el $\mathrm{Cl}$ es un proceso, no un documento, y el impreso firmado no es más que una prueba entre otras de que el proceso está teniendo lugar", p. 9. 
alto ${ }^{26}$, requieran, indiscutiblemente, una reforzada protección jurídica con las máximas garantías y cautelas ${ }^{27}$. En la práctica, una excesiva burocratización del $\mathrm{Cl}$ en el contexto biomédico a fin de lograr el objetivo de exonerar de responsabilidad al sujeto fuerte ${ }^{28}$, podría dejar al débil en una situación de clara mutilación de sus derechos fundamentales.

Una detenida exégesis de la LIB y del RD 2011 en lo que se refiere a la regulación del $\mathrm{Cl}$ para la recogida y cesión de muestras biológicas pertenecientes a mayores de edad con discapacidad (con o

26 El respeto de los derechos fundamentales de los pacientes es contemplado tanto por el Código de Nüremberg de 20 de agosto de 1947, en el cual se recogen los principios orientativos de la experimentación médica en seres humanos, como por la Declaración de Helsinki de la Asociación Médica Mundial relativa a los trabajos de investigación biomédica con sujetos humanos.

Conforme al art. 3 de la Carta de los Derechos fundamentales de la Unión Europea de 2000, el cual se ocupa del derecho a la integridad de la persona: "1. Toda persona tiene derecho a su integridad física y psíquica. 2. En el marco de la medicina y la biología se respetarán en particular:- el consentimiento libre e informado de la persona de que se trate, de acuerdo con las modalidades establecidas en la ley [...]".

27 El Informe Belmont. Principios y guías éticos para la protección de los sujetos humanos de investigación. Comisión Nacional para la protección de los sujetos humanos de investigación biomédica y del comportamiento U.S.A. de 1979, dentro del principio del respeto a las personas dispone: "El respeto a las personas incorpora cuando menos dos convicciones éticas: primero, que los individuos deberán ser tratados como agentes autónomos y segundo, que las personas con autonomía disminuida tienen derecho a ser protegidas. Así, el principio de respeto a las personas se divide en dos exigencias morales separadas: la exigencia de reconocer autonomía y la exigencia de proteger a aquellos con autonomía disminuida... La capacidad para hacer decisiones propias madura en el transcurso de la vida del individuo y algunos individuos pierden esta capacidad total o parcialmente debido a enfermedad, incapacidad mental o circunstancias que limitan su libertad severamente. Las personas inmaduras o incapacitadas pueden requerir protección en lo que se refiere al respeto que merecen mientras estén incapacitadas.Algunas personas necesitan protección completa, al punto de excluirlos de actividades que puedan lastimarlos; otras personas requieren escasa protección más allá de asegurarse que participan en actividades por su propia voluntad y con conciencia de las posibles consecuencias adversas. La cantidad de protección suministrada debe depender del riesgo de daño y la probabilidad de beneficio. La decisión de que algún individuo carece de autonomía deberá evaluarse periódicamente y variará en situaciones diferentes. En la mayoría de los casos de investigación incluyendo sujetos humanos, el respeto a las personas exige que los sujetos participen en la investigación voluntariamente y con información adecuada. Sin embargo, en algunas situaciones la aplicación del principio no es obvia". Por su parte, el art. 8 de la Declaración Universal sobre bioética y derechos humanos de 19 de octubre de 2005 dispone: "Al aplicar y fomentar el conocimiento científico, la práctica médica y las tecnologías conexas, se debería tener en cuenta la vulnerabilidad humana. Los individuos y grupos especialmente vulnerables deberían ser protegidos y se debería respetar la integridad personal de dichos individuos".

28 Acerca de la responsabilidad en la realización de actividades de bioinvestigación, vid. Romero Pareja (2012, p.18-24). 
sin capacidad modificada), nos permitirá comprobar si sus disposiciones normativas encuentran o no acomodo en las directrices marcadas tanto por los Tratados Internacionales como por la legislación nacional (civil y sanitaria) específica y que configuran el estatuto jurídico de las personas frágiles, si los derechos de las personas con discapacidad resultan debidamente salvaguardados por nuestro legislador, al tiempo que plantearemos algunas dudas interpretativas que nos suscitan las imprecisiones u omisiones técnicas cometidas en la redacción de uno y otro texto normativo ${ }^{29}$, labor ésta que nos dará pie a realizar recomendaciones o propuestas de lege ferenda de cara a la inminente regulación autonómica de los $\mathrm{BB}^{30}$.

En términos generales, podemos afirmar que el marco legal integrado por la LIB y el RD 2011 brinda un adecuado tratamiento del $\mathrm{Cl}$ de las personas vulnerables, siendo algunos de sus puntos todo

29 Sirva de ejemplo la LIB, que en la delimitación de su objeto, en su art. 1.1 dispone que "esta Ley tiene por objeto regular, con pleno respeto a la dignidad e identidad humanas y a los derechos inherentes a la persona, la investigación biomédica [...]" y en su art. 2.1.a) establece: "la realización de cualquier actividad de investigación biomédica comprendida en esta Ley estará sometida a la observancia de las siguientes garantías: a) Se asegurará la protección de la dignidad e identidad del ser humano con respecto a cualquier investigación que implique intervenciones sobre seres humanos en el campo de la biomedicina, garantizándose a toda persona, sin discriminación alguna, el respeto a la integridad y a sus demás derechos y libertades fundamentales". De este modo, el legislador, al mencionar los "derechos inherentes" genera una duda interpretativa en cuanto si por tales ha de entenderse los derechos y libertades fundamentales reconocidos en nuestra CE o, en cambio, aquéllos tienen un alcance jurídico distinto.

30 Al cierre del presente trabajo, las únicas Comunidades Autónomas que cuentan con una normativa sobre BB es Valencia (Decreto 143/2008, de 3 de octubre, de la Generalitat Valenciana, que establece los requisitos organizativos y operativos de los biobancos, regula el procedimiento administrativo de autorización de biobancos y crea la Red de Biobancos de la Comunidad Valenciana), Andalucía (Decreto 1/2013, de 8 de enero, por el que se regula la autorización para la constitución y funcionamiento de biobancos con fines de investigación biomédica, se crean el Registro de Biobancos de Andalucía y el Biobanco del Sistema Sanitario Público de Andalucía), Aragón (Decreto 146/2013, de 29 de agosto, del Gobierno de Aragón, por el que se determina la autoridad competente para autorizar la constitución y funcionamiento de los biobancos con fines de investigación biomédica en la Comunidad Autónoma de Aragón, y se crea el Biobanco del Sistema de Salud de Aragón), y Cataluña (Decreto 234/2013, de 15 de octubre, por el que se regulan la autorización para la constitución y el funcionamiento de los biobancos con fines de investigación biomédica en Cataluña y de la Red Catalana de Biobancos). El RD 2011 indica que las Comunidades Autónomas son competentes para autorizar la constitución y funcionamiento de los biobancos en sus ámbitos competenciales respectivos, sin perjuicio de las competencias atribuidas al Ministerio de Ciencia e Innovación para la creación de biobancos nacionales. 
un acierto, en tanto que otros son confusos o controvertidos y, por tanto, en su aplicación práctica, han de ser objeto de una cuidadosa y rigurosa interpretación que no consienta arbitrariedad alguna. Todo ello ha de servir de guía para que las leyes autonómicas reguladoras de los BB desarrollen adecuadamente las normas básicas estatales, perfeccionando con mejor técnica legislativa sus ambiguas y deficientes disposiciones y no limitándose, sin más, a reproducirlas.

En relación a las personas con discapacidad, la LIB se preocupa por garantizar la plena accesibilidad de la información que ha de ser suministrada con carácter previo al otorgamiento del consentimiento, en tanto que en cuanto a las personas incapacitadas judicialmente, si bien el $\mathrm{Cl}$ es prestado por representación, su intención es involucrarlas activamente a lo largo del proceso de investigación. Por su parte, el RD 2011 no se ocupa ni de unas ni de otras, limitándose únicamente a contemplar el supuesto de almacenamiento y conservación de muestras biológicas de sujetos fuente menores de edad, si bien entendemos aplicable lo dispuesto respecto al $\mathrm{Cl}$ por la LIB, que aquél desarrolla reglamentariamente, pues, como expresa en su Exposición de Motivos,

el Real Decreto distingue entre el régimen general para el tratamiento de muestras biológicas con fines de investigación biomédica y el régimen específico que ha de aplicarse cuando este tratamiento se lleva a cabo en un biobanco. En ambos casos, se insiste en la vinculación a los principios establecidos en la Ley 14/2007, de 3 de julio, con un énfasis especial en la necesidad de consentimiento expreso y escrito para la obtención y utilización de las muestras, en la obligación de respetar el derecho a la intimidad y a la autodeterminación informativa, y en la gratuidad de todo el proceso de tratamiento de las muestras.

Ambos textos normativos tienen por finalidad proteger a la persona respecto al derecho de información, sus datos personales y confidencialidad de los mismos en las investigaciones en las cuales participan, si bien, a nuestro entender, no son todo lo garantistas de sus derechos fundamentales que hubiera sido deseable, en concreto, 
con la libre autonomía de la persona vulnerable ${ }^{31}$. La garantía del consentimiento en caso de personas frágiles es, sin duda alguna, insuficiente, siendo éste uno de los aspectos más criticables de la LIB, por su imperdonable falta de sensibilidad.

Junto a la vulnerabilidad de una persona, ha de tenerse muy en cuenta que las muestras biológicas que se incorporen a los BB pueden ser utilizadas para cualquier investigación biomédica (la vocación de servicio público de los BB hace imprescindible para su funcionamiento que el consentimiento del sujeto fuente incluya la cesión de las muestras en términos más amplios que cuando se trata de muestras depositadas en colecciones, puesto que, en este último caso, es preciso un consentimiento expreso para cada cesión ex art. 22.2 RD 2011), esto es, al cedente de la muestra sólo se le pedirá un consentimiento que servirá para todas las investigaciones biomédicas en las que se utilice su material biológico, de lo que puede deducirse la magnitud y trascendencia de esta cuestión y la importancia de sus consecuencias jurídicas (estigmatización, discriminación, etc.), mayor aún si se tiene en cuenta que el cedente no será quien preste directamente dicho consentimiento sino que otras personas lo harán por él.

Pese a ello, nos da la impresión de que los requisitos del $\mathrm{Cl}$ se relajan con el fin de que se cumplan los objetivos de los biobancos de muestras biológicas de origen humano, cuando, más bien, debería haber sido al contrario, al estar en juego derechos fundamentales de personas con voluntad y libertad limitadas. En la tensión entre el respeto de la dignidad de la persona y el derecho a la investigación científica, el legislador se ha inclinado, sin ninguna duda, por esta última.

Además, cabe pensar que la confusa regulación del consentimiento del sujeto fuente frágil no va a resolver todos los problemas que pueden plantearse en la práctica en un ámbito en el que los profesionales

31 Como recoge Durán Lalaguna (2008, p. 11), "hay quien considera que la Ley resulta débil en el lenguaje de protección de menores, personas con discapacidad e incapaces". 
necesitan pautas claras y seguras a seguir a fin de evitar eventuales reclamaciones de responsabilidad.

\subsection{Personas con capacidad judicialmente modificada}

Comenzando por la terminología, la LIB alude a las "personas incapacitadas" (art. 4.2), pareciéndonos más adecuada la de "personas con capacidad modificada judicialmente", utilizada ya por el Real Decreto 1276/2011, de 16 de septiembre, de adaptación normativa a la Convención Internacional sobre los derechos de las personas con discapacidad, que modifica el Real Decreto 1301/2006, de 10 de noviembre, por el que se establecen las normas de calidad y seguridad para la donación, la obtención, la evaluación, el procesamiento, la preservación, el almacenamiento y la distribución de células y tejidos humanos y se aprueban las normas de coordinación y funcionamiento para su uso en humanos ${ }^{32}$, así como por la Ley 20/2011, de 21 de julio, del Registro Civil (norma que, con alguna excepción, aún no ha entrado en vigor). Si bien, por fecha, la LIB no podía haber acogido la terminología apuntada, no entendemos cómo la Ley 26/2011, de 1 de agosto, de adaptación normativa a la Convención Internacional sobre los Derechos de las Personas con Discapacidad no ha procedido a retocarla debidamente.

La LIB establece que "las personas incapacitadas... participarán en la medida de lo posible y según su edad y capacidades en la toma de decisiones a lo largo del proceso de investigación" (art. 4.2), si bien intuimos que la práctica conduce al no entorpecimiento de la investigación científica y, por consiguiente, a la cómoda obtención del consentimiento por representación.

32 En concreto, el segundo párrafo del apartado 1 del art. 8 del RD 1301/2006, de 10 de noviembre queda modificado en los siguientes términos: "En el caso de que se trate de menores o personas con capacidad modificada judicialmente, la oposición a la donación podrá hacerse constar por quienes hubieran ostentado en vida de aquellos su representación legal. Tratándose de personas con discapacidad, deberán tenerse en cuenta las circunstancias personales del individuo, su capacidad para tomar dicha decisión en concreto y contemplarse la prestación de apoyo para la toma de estas decisiones". 
En el RD 2011 se omite por completo el tratamiento de las muestras biológicas procedentes de personas incapacitadas judicialmente, teniéndose en cuenta, exclusivamente, a los menores de edad en cuanto a la garantía para el acceso de la información cuando alcancen la mayoría de edad (arts. 23.n) y 32.3). ¿Significa ello que las personas con capacidad de obrar modificada judicialmente que posteriormente la recuperen no tienen reconocida tal garantía? Imposible, de modo que sólo podemos pensar en un lamentable descuido por parte del legislador, para quien el menor de edad es tendencialmente capaz, de modo que su vulnerabilidad es sólo temporal, no, en cambio, la persona incapacitada judicialmente, cuya situación parece irreversible. Curiosamente, el legislador sí ha previsto que la persona incapaz de consentir debido a su situación clínica pueda, con posterioridad, recuperar su autonomía y, por consiguiente, hallarse en condiciones de prestar el consentimiento (art. 21.4 LIB). Una vez más e inexplicablemente, el menor, goza de condiciones legales notablemente mejores que el incapacitado judicialmente, suponiendo ello un inaceptable agravio comparativo para este último.

La normativa en estudio parte de una persona declarada judicialmente incapacitada que sólo puede prestar por sí misma consentimiento si "en atención a su grado de discernimiento, la resolución judicial de incapacitación le autorizase para prestar su consentimiento a la investigación” (art. 20.1 LIB). En caso contrario, el Cl se obtiene por representación.La fórmula legal empleada no es, a nuestro juicio, afortunada.

El legislador estatal parte, implícitamente, de la incapacitación total (en la parcial el sistema de guarda es la curatela y, como es sabido, el curador no es un representante legal) e irreversible, como permite deducir la falta de previsión por parte del RD 2011 de una eventual recuperación de la capacidad.

Súmese a lo anterior que, con escasa frecuencia, se hace constar expresa y detalladamente en las sentencias judiciales, el concreto alcance del autogobierno de la persona con capacidad de obrar modificada en relación al otorgamiento del $\mathrm{Cl}$ en el ámbito de la salud y, en particular, en 
el contexto de la bioinvestigación. Ojalá los pronunciamientos judiciales mencionaran explícitamente si la modificación de la capacidad de la persona comprende o no este extremo (así como tantos otros). Los pocos que lo hacen utilizan una fórmula un tanto ambigüa y, a nuestro juicio, por excesiva y rígida, poco respetuosa con la persona y muy alejada del deseado "traje a medida", pues se declara que la persona no es capaz de: "tomar decisiones y otorgar consentimiento válido informando para cualquier intervención o tratamiento médico"33.

Al respecto, hemos de recordar que la incapacitación judicial no implica necesariamente la pérdida de la posibilidad de ejercitar los derechos de la personalidad de la persona incapacitada, salvo que la sentencia establezca lo contrario, de ahí que, en nuestra opinión, sea preciso atender a las circunstancias del caso y a las concretas facultades cognitivas y volitivas del sujeto fuente. Es más, con frecuencia, las personas con capacidad judicialmente modificada son competentes para tomar decisiones sobre su salud, incluso, aun no siéndolo para tomar decisiones de otra índole (vgr. la venta de un bien inmueble). El sujeto incapacitado puede estar atravesando un periodo de lucidez, o

33 Tal fórmula puede encontrarse en la SAP de Vizcaya (Sección 4. ${ }^{a}$ ) de 18 de enero de 2010 (JUR 2010, 149718), la cual estima el recurso de apelación interpuesto contra la sentencia de instancia, establece, en el ámbito personal, que el demandado no tiene capacidad de obrar y no puede actuar por sí solo y prestar consentimiento válido en relación a la "toma de decisiones y otorgamiento de consentimiento informado válido para cualquier intervención o tratamiento médico, con especial atención al sometimiento y tratamiento psiquiátrico y/o farmacológico e incluso internamiento que precise por su enfermedad de trastorno delirante que incide sobre una personalidad de tipo paranoide". Por su parte, la SAP de Asturias (Sección 5a) de 29 de noviembre de 2010 (AC 2010, 2378), la cual utiliza la terminología "modificar la capacidad de obrar", confirmando la sentencia de primera instancia, declara que el demandado "no tiene capacidad de obrar y habilidades necesarias para actuar, por sí solo, y prestar consentimiento válido en relación a:

1)- Decidir el lugar donde residirá.

2)- Tomar decisiones y otorgar consentimiento válido e informado sobre pautas alimenticias, higiénicas y demás actuaciones de la vida personal.

3)- Tomar decisiones y otorgar consentimiento válido informando para cualquier intervención o tratamiento médico.

4)- Para realizar actuaciones complejas o de administración de su patrimonio.

5)- No puede otorgar testamento.

6)- No puede otorgar poderes.

7)- No puede entablar acciones judiciales.

8)- No puede otorgar, por sí solo, consentimiento válido en contratos o negociaciones jurídicas que afecten a su persona o a su patrimonio.

9)- Carece de capacidad para ejercer el derecho de sufragio activo y pasivo". 
simplemente, su grado de incapacidad no le impide entender el acto de obtención de la muestra ni su destino posterior a fines de investigación biomédica, con independencia de que la posibilidad de realizar dicho acto por sí mismo conste o no en la sentencia judicial ${ }^{34}$. Creemos que ello es acorde con lo dispuesto en la Convención ONU sobre los derechos de las personas con discapacidad.

La letra de la ley nos suscita algunas dudas: ¿qué sucede si cuando se precisa el CI para la obtención y posterior cesión de la muestra biológica está en curso el procedimiento judicial de modificación de la capacidad? Entendemos que ante la falta de resolución judicial firme de incapacitación, la solución debe ser la misma que para la persona incapaz carente de representación legal y, por tanto, del art. $21.3^{\circ} \mathrm{LIB}$ parece deducirse que el consentimiento sería prestado por las personas que convivieran (la LIB no especifica si han de ser familiares o no) con el presunto incapaz.

Idéntica solución ha de predicarse de aquellos casos anteriores a la entrada en vigor de la LEC-2000 35 , en los que se declararon personas judicialmente incapacitadas pero, con posterioridad, no se siguió otro procedimiento para nombrar el correspondiente sistema de guarda.

34 Como señala, en relación a la LAP, Parra Lucán (2003) “no puede entenderse, en consecuencia, que para los incapacitados el consentimiento lo preste, sin más, el representante legal. Aun estando incapacitado, es discutible que la sentencia de incapacitación pueda excluir toda decisión del incapacitado relativa al ejercicio de los derechos de la personalidad".

35 Es importante destacar (por el gran acierto que ello ha supuesto) que con la LEC-2000 (arts. 759.2 y 760.2), si en el escrito inicial de solicitud de la incapacidad se solicita, además, la constitución del régimen de guarda y el nombramiento de la persona concreta (física o jurídica) que ha de asumirla, la sentencia que declare la incapacidad nombrará también al representante legal o asistente, de tal forma que no habrá de iniciarse, tras la firmeza de la sentencia, un expediente de jurisdicción voluntaria, tal y como ocurría bajo la LEC-1881 y que demoraba, notoriamente, la resolución de la situación. Ahora, pues, en aras del principio de economía procesal, puede obtenerse, al mismo tiempo, la sentencia de incapacitación y el nombramiento de las personas que deban representar o asistir a los incapacitados, lo que agiliza notablemente las cosas.

Acerca de los inconvenientes que generaba el régimen anterior a la LEC-2000, Comes MUÑOZ, E.; Escalonilla Morales, B. Mª (2007, p. 189-190), señalan: "vemos, con más frecuencia de lo deseable, que se promueven expedientes de jurisdicción voluntaria para el nombramiento de tutor de personas que fueron incapacitadas antes de la entrada en vigor de la LEC de 2000, varios años después de que el interesado fuera declarado incapaz por sentencia hasta once años después, como ocurrió recientemente en uno de los procedimientos tramitados ante los juzgados de tutelas de Madrid. Desde estos Juzgados se ha detectado además que la imposibilidad pretérita de poder acumular ambas acciones de incapacitación y nombramiento de tutor ha creado una bolsa de incapacitados no tutelados: todos aquellos que, tras dictarse la correspondiente sentencia en el procedimiento de menor cuantía, ni sus familiares ni el Ministerio Fiscal han instado el preceptivo nombramiento de tutor o curador". 
En caso de persona en internamiento en un centro psiquiátrico, ¿es el juez quien ha de emitir el consentimiento? Consideramos que sí, pero la LIB nada dice al respecto.

\subsection{Personas con discapacidad}

La LIB, al regular el $\mathrm{Cl}$ y el derecho a la información en su art. 4 , tiene presente a las personas con discapacidad, a quienes alude utilizando una correcta terminología, siguiendo, así, el mandato de la Disposición Adicional $8^{a}$ de la Ley 39/2006, de 14 de diciembre de 2006, de Promoción de la Autonomía Personal y Atención a las personas en situación de Dependencia ${ }^{36}$.

Sin embargo, el legislador de 2007 no proporciona ninguna definición, a efectos de la Ley, de "persona con discapacidad"37, de tal

36 Disposición Adicional $8^{a}$ de la Ley de Dependencia: "Terminología.Las referencias que en los textos normativos se efectúan a 'minusválidos' y a 'personas con minusvalía', se entenderán realizadas a personas con discapacidad. A partir de la entrada en vigor de la presente Ley, las disposiciones normativas elaboradas por las Administraciones Públicas utilizarán los términos persona con discapacidad'o 'personas con discapacidad' para denominarlas".

37 Consideramos que no es aplicable, en el ámbito de la investigación biomédica, el concepto de "persona con discapacidad" que proporciona el art. 2.2 de la Ley 41/2003, de 18 de noviembre, de protección patrimonial de las personas con discapacidad y de modificación del Código Civil, de la Ley de Enjuiciamiento Civil y de la Normativa Tributaria con esta finalidad, ante su claro tenor literal: "2. A los efectos de esta Ley únicamente tendrán la consideración de personas con discapacidad: a. Las afectadas por una minusvalía psíquica igual o superior al $33 \%$. b. Las afectadas por una minusvalía física o sensorial igual o superior al $65 \%$. 3. El grado de minusvalía se acreditará mediante certificado expedido conforme a lo establecido reglamentariamente o por resolución judicial firme". Por su parte, el apdo. 2 del art. 1 de la Ley 51/2003, de 2 de diciembre, de igualdad de oportunidades, no discriminación y accesibilidad universal de las personas con discapacidad, recientemente modificado por la Ley 26/2011, de 1 de agosto, de adaptación normativa a la Convención Internacional sobre los Derechos de las Personas con Discapacidad, ha pasado a disponer lo siguiente: "2. Son personas con discapacidad aquellas que presenten deficiencias físicas, mentales, intelectuales o sensoriales a largo plazo que, al interactuar con diversas barreras, puedan impedir su participación plena y efectiva en la sociedad, en igualdad de condiciones con los demás. Las medidas de defensa, de arbitraje y de carácter judicial, contempladas en esta Ley serán de aplicación a las personas con discapacidad, con independencia de la existencia de reconocimiento oficial de la situación de discapacidad o de su transitoriedad. En todo caso, las Administraciones públicas velarán por evitar cualquier forma de discriminación que afecte o pueda afectar a las personas con discapacidad. Ello no obstante, a los efectos de esta Ley, tendrán la consideración de personas con discapacidad aquellas a quienes se les haya reconocido un grado de discapacidad igual o superior al 33 por ciento. En todo caso, se considerarán que presentan una discapacidad en grado igual o superior al 33 por ciento los pensionistas de la Seguridad Social que tengan reconocida una pensión de incapacidad permanente en el grado de total, absoluta o gran invalidez, y a los pensionistas de clases pasivas que tengan reconocida una pensión de jubilación o de retiro por incapacidad permanente para el servicio o inutilidad. La acreditación del grado de discapacidad se realizará en los términos establecidos reglamentariamente y tendrá validez en todo el territorio nacional". 
forma que desconocemos si está pensando en los porcentajes según los tipos de discapacidad debidamente acreditados o bien utiliza un concepto distinto a los únicos efectos de la LIB.

La LIB se encuentra en sintonía con la Convención ONU sobre los derechos de las personas con discapacidad en relación a la enorme importancia que reviste para las personas con discapacidad el respeto a su autonomía individual, incluida la libertad de tomar decisiones, su voluntad, sus preferencias (Preámbulo, letra $n$ y arts. 3 y 12.4) y a la accesibilidad informativa (art. 9). Conforme a ello, el art. 4.1, pfo. $3^{\circ}$ LIB establece que la información que ha de proporcionarse a las personas con discapacidad con carácter previo al consentimiento se les prestará "en condiciones y formatos accesibles apropiados a sus necesidades".

Al respecto, hemos de destacar que Ley 26/2011, de 1 de agosto, de adaptación normativa a la Convención Internacional sobre los Derechos de las Personas con discapacidad, ha modificado el art. 10 de La Ley 14/1986, de 25 de abril, General de Sanidad, que pasa a disponer lo siguiente:

1. Todos tienen los siguientes derechos con respecto a las distintas Administraciones públicas sanitarias:

Al respeto a su personalidad, dignidad humana e intimidad, sin que pueda ser discriminado por su origen racial o étnico, por razón de género y orientación sexual, de discapacidad o de cualquier otra circunstancia personal o social.

2. A la información sobre los servicios sanitarios a que puede acceder y sobre los requisitos necesarios para su uso. La información deberá efectuarse en formatos adecuados, siguiendo las reglas marcadas por el principio de diseño para todos, de manera que resulten accesibles y comprensibles a las personas con discapacidad.

En el mismo sentido, la citada Ley de 2011 modifica asimismo el apartado $5^{\circ}$ del art. 9 de la LAP, en los siguientes términos:

5. ...Si el paciente es una persona con discapacidad, se le ofrecerán las medidas de apoyo pertinentes, incluida la información en formatos adecuados, siguiendo las reglas marcadas por el principio del diseño para todos de manera 
que resulten accesibles y comprensibles a las personas con discapacidad, para favorecer que pueda prestar por sí su consentimiento.

Por su parte, el RD 1276/2011, de 16 de septiembre, de adaptación normativa a la Convención Internacional sobre los derechos de las personas con discapacidad modifica el RD 1301/2006, de 10 de noviembre, por el que se establecen las normas de calidad y seguridad para la donación, la obtención, la evaluación, el procesamiento, la preservación, el almacenamiento y la distribución de células y tejidos humanos y se aprueban las normas de coordinación y funcionamiento para su uso en humanos, al que añade un nuevo apartado 3 al art. 7 con la siguiente redacción:

3. La información y el consentimiento deberán efectuarse en formatos adecuados, siguiendo las reglas marcadas por el principio de diseño para todos, de manera que resulten accesibles y comprensibles a las personas con discapacidad.

Repárese en que la buena redacción técnica de la LIB en esta concreta cuestión ha hecho innecesaria su modificación por la citada Ley 26/2011, de 1 de agosto, si bien, a nuestro juicio, nos parece más ajustada al citado Tratado Internacional la fórmula "la información y el consentimiento deberán efectuarse en formatos adecuados, siguiendo las reglas marcadas por el principio de diseño para todos, de manera que resulten accesibles y comprensibles a las personas con discapacidad", pues contempla el formato no sólo de la información a proporcionar (como hace la LIB), sino también de la hoja del consentimiento (con independencia de que ambas se contengan en documentos separados o en único documento), documentos ambos a los cuales ha de exigirse que sean no sólo "accesibles" (único requisito previsto por la LIB), sino también y fundamentalmente "comprensibles" (término utilizado por la LIB en su art. 15.1, si bien en términos generales y no específicamente para las personas con discapacidad), lo cual es esencial en una materia repleta de tecnicismos científicos. 
Ha de tenerse en cuenta que a todo sujeto fuente mayor de edad no incapacitado judicialmente, pese a tener una discapacidad intelectual, se le presume su plena capacidad de obrar, de modo que tiene capacidad de comprender la información necesaria para tomar una decisión. Cosa distinta es que necesite información adicional o que ésta le sea suministrada en un formato accesible y fácilmente comprensible, además del tiempo suficiente para reflexionar y decidir con entera libertad.

Así las cosas, debe lograrse la efectividad de la tutela de las personas con discapacidad y el respeto a la persona humana y a su derecho a la libertad suprimiéndose todas las barreras de comunicación a fin de garantizar a la persona frágil la plena accesibilidad en la recepción de la información antes de prestar su $\mathrm{Cl}$.

De este modo, en caso de persona con discapacidad auditiva ha de contarse con la presencia de un intérprete de lengua de signos ${ }^{38}$ y tratándose de discapacidad visual debe ofrecerse el acceso a la información en formato Braille. La LIB parece estar pensando en ello al contemplar la información que ha de suministrarse a un sujeto con discapacidad participante en una investigación que implique procedimiento invasivo en seres humanos (art. 15.1: "[...] y cuando se trate de personas con discapacidad de forma adecuada a sus circunstancias"), si bien la regulación podría haber sido más minuciosa y explícita.

Dado que la LIB parte de la exigencia de un consentimiento "expreso y escrito"39" (arts. 4.1, 13 y 48), la cual, a nuestro entender,

38 "Art. 10.c) de la Ley $27 / 2007$, de 23 de octubre, por la que se reconocen las lenguas de signos españolas y se regulan los medios de apoyo a la comunicación oral de las personas sordas, con discapacidad auditiva y sordociegas".

39 El art. 8 de la LAP contempla, en cambio, un otorgamiento del consentimiento verbal, salvo para casos concretos en los cuales será escrito: "El consentimiento será verbal por regla general. Sin embargo, se prestará por escrito en los casos siguientes: intervención quirúrgica, procedimientos diagnósticos y terapéuticos invasores y, en general, aplicación de procedimientos que suponen riesgos o inconvenientes de notoria y previsible repercusión negativa sobre la salud del paciente". 
encuentra justificación en motivos garantistas del cumplimiento efectivo del derecho al $\mathrm{Cl}$ pero también de índole probatoria con vistas a posibles reclamaciones de responsabilidad, el legislador añade: "si el sujeto de la investigación no pudiera escribir, el consentimiento podrá ser prestado por cualquier medio admitido en Derecho que permita dejar constancia de su voluntad" (art. $4.1^{\circ}$ últ. pfo.).

Al respecto, nos preguntamos si, en tales casos, son admisibles para dejar constancia de la voluntad del sujeto fuente: ¿una grabación en vídeo? ¿consentimiento expresado de forma oral con presencia de, al menos, un testigo ${ }^{40}$ o mediante impresión de su huella digital en caso de que la persona no sepa escribir?

Como puede observarse, la LIB se preocupa, exclusivamente, de suprimir las barreras físicas, en concreto, la accesibilidad de la información, pero no las barreras psicológicas, los sentimientos de desconfianza y angustia, los temores e inseguridades de la persona frágil en el escenario bioinvestigador.

A diferencia de la LIB, el RD 2011 no hace mención alguna a las personas con discapacidad.

\subsection{Personas incapaces de hecho}

Una persona tiene una incapacidad de hecho cuando carece de entendimiento y voluntad suficientes para gobernar su vida por sí mismas de forma autónoma, temporal o permanentemente, sin haber recaído resolución judicial firme de incapacitación. Nos referimos a situaciones en las que la persona, por diversas razones, tiene seriamente comprometido su discernimiento (ej. pérdida de conocimiento, coma, etc.). En otras palabras, es jurídicamente capaz pero no de facto, de modo que no tiene representantes legales.

40 Así dispone la letra m), pfo. $2^{\circ}$ del art. 2 del Real Decreto 223/2004, de 6 de febrero, por el que se regulan los ensayos clínicos con medicamentos, tras su redacción por el RD. 1276/2011, de 16 de septiembre, de adaptación normativa a la Convención Internacional sobre los derechos de las personas con discapacidad. 
De ello se ocupa el art. 21 LIB:

Investigación en personas incapaces de consentir debido a su situación clínica.

1. Para la realización de una investigación en situaciones clínicas de emergencia, en las que la persona implicada no pueda prestar su consentimiento, deberán cumplirse las siguientes condiciones específicas:

a) Que no sea posible realizar investigaciones de eficacia comparable en personas que no se encuentren en esa situación de emergencia.

b) Que en el caso de que no sea previsible que la investigación vaya a producir resultados beneficiosos para la salud del paciente, tenga el propósito de contribuir a mejorar de forma significativa la comprensión de la enfermedad o condición del paciente, con el objetivo de beneficiar a otras personas con la misma enfermedad o condición, siempre que conlleve el mínimo riesgo e incomodidad para aquél.

c) Que la autorización de la investigación se ponga en conocimiento del Ministerio Fiscal.

El propio legislador, en el apartado $3^{\circ}$ del mismo precepto, define las investigaciones en situaciones de emergencia como

aquéllas en las que la persona no se encuentre en condiciones de otorgar su consentimiento y, a causa de su estado y de la urgencia de la situación, sea imposible obtener a tiempo la autorización de los representantes legales del paciente o, de carecer de ellos, de las personas que convivieran con aquél.

Ante estas situaciones, el legislador se ha olvidado de la posibilidad de que la persona hubiera otorgado un poder o mandato a favor de una (o varias) persona de confianza facultándola para la gestión de sus asuntos personales y patrimoniales (representación voluntaria), y que, con posterioridad, le sobrevenga una incapacidad (declarada judicialmente o no) al mandante. Pues bien, en tal caso el mandato se acaba o extingue conforme a lo dispuesto por el art. 1732, últ. pfo. C.c., salvo que (novedad ésta introducida en 2003 por la Ley 41/2003, de 18 de 
noviembre, de protección patrimonial de las personas con discapacidad y de modificación del Código civil, de la Ley de Enjuiciamiento civil y de la Normativa Tributaria con esta finalidad) el mandante hubiera dispuesto expresamente su continuación a pesar de la incapacitación o bien que el poder se hubiera dado, precisamente, para el caso de incapacidad del mandante apreciada conforme a lo dispuesto por éste (p. ej. según dictamen de un médico propuesto por el mandante, cuando sobrepase un determinado porcentaje de discapacidad, etc. $)^{41}$.

Asimismo, como ya se apuntó y ahora insistimos, pueden ser útiles las llamadas instrucciones previas, voluntades anticipadas o testamento vital.

Naturalmente, el legislador establece la necesidad de respetar cualquier objeción expresada previamente por el paciente que sea conocida por el médico responsable de su asistencia, por el investigador o por el Comité de Ética de la Investigación correspondiente al centro (art. 21.2 LIB).

\section{Conclusão}

Partiendo de que tanto el derecho a la salud como el de autodeterminación son derechos personalísimos, a fin de expresar su consentimiento/disenso informado, la persona con discapacidad (con capacidad judicialmente modificada o no) tan sólo precisa de alguien que le ayude a comprender la decisión a adoptar y su trascendencia, a superar sus miedos y dudas injustificadas ${ }^{42}$. Para ello no ha de incapacitarse a la persona; basta con nombrarle una persona de apoyo, como el amministratore di sostegno italiano o el asistente catalán, un compañero de camino, un "ángel de la guarda", que no tome decisiones "por" la persona sino "con" ella.

\footnotetext{
41 Del mandato preventivo hemos tenido ocasión de ocuparnos en nuestro trabajo ya citado $L a$ dignidad de las personas con discapacidad: logros y retos jurídicos, en concreto, p. 121-123.

42 S. Trib. de Venecia de 20 de septiembre de 2006.
} 
Desde la Convención ONU sobre los derechos de las personas con discapacidad, es ése el único horizonte posible.

\section{Referências}

ALLEN, J.; MCNAMARA, B. Reconsidering the value of consent in biobank research. Bioethics, New York, v. 25, n. 3, p. 155-166, 2009.

AZZINI, S.; AZZINI, S. Biobanche, consenso e fonti del Diritto: un caso si eccezionale disordine. En: CASONATO, PICIOCCHI; VARONESI. La disciplina delle biobanche ai fini terapeutici e di ricerca. Università di Trento, 2012. p. 117-150. Disponivel em: <http://eprints.biblio.unitn. it/3979/1/casonato_piciocchi_veronesi_quaderno_101_versione_ corretta_giov19apr2012.pdf>. Acesso em: 12 abr. 2016.

CASADO DE LA ROCHA, A.; ETXEBARRÍA AGIRIANO, A. EI consentimiento informado ante los biobancos y la investigación genética. Arbor Ciencia, Pensamiento y Cultura, Madrid, n. 730, p. 249-260, 2008.

CASADO DE LA ROCHA, A. Biobancos, cultura científica y ética de la investigación. Dilemata, Madrid, año 2, n. 4, p. 1-14, 2010.

CLAYTON, E. W. Informed Consent and Biobanks. The Journal of Law, Medicine \& Ethics, New York, v. 33, issue 1, p. 15-21, 2005.

COMES MUÑOZ, E.; ESCALONILLA MORALES, B. M. Discapacidad y procedimiento de incapacitación. En: LAORDEN, J. (dir.); TERREROS, J. L. (Coord.). Los derechos de las personas con discapacidad: aspectos jurídicos. Madrid: CGPJ, 2007. v. I. p. 189-190.

DE ROBBIO, A.; CORRADI, A. Biobanche in bilico tra proprietà privata e beni comuni: brevetti o open data sharing? JLIS.it., Firenze v. 1, n. 2, 2010.

DÍAZ MARTÍNEZ, A. Daños causados en la investigación biomédica y la realización de estudios genéticos: conductas y omisiones determinantes de responsabilidad y resarcimiento. La Ley, Madrid, n. 6782, sep. 2007. p. 1671-1679. 
DÍAZ MARTÍNEZ, A. El consentimiento informado como garantía del derecho fundamental a la integridad física y moral. Aranzadi CivilMercantil, Aranzadi, n. 5, p. 25-35, 2011.

DURÁN LALAGUNA, P. Cuestiones de investigación biomédica. Madrid: Fundación Ciudadanía y Valores, 2008.

FERIOLI, E.; PICOZZI, M. La conservazione del materiale biologico finalizzato alla ricerca scientifica: questioni giuridiche e riflessioni etiche sulle biobanche. Medicina e morale, Roma, n. 4, v. 61, p. 553-584, 2011.

GANZENMÜLLER ROIG, C. (Dir.). Conclusiones de las jornadas de fiscales especializados en la protección de las personas con discapacidad y tutelas del 19 y 20 de octubre de 2009: la efectiva aplicación de la Convención de Naciones Unidas sobre los derechos de las personas con discapacidad y sus efectos en el Derecho interno. Madrid, 2009. Disponível em: <https://www.fiscal.es/ fiscal/PA_WebApp_SGNTJ_NFIS/descarga/CONCLUSIONES\%20 JORNADAS\%20DE\%20FISCALES. pdf?idFile=6433245e-22f9-4531953f-24f39027a998>. Acesso em: 25 mar. 2015.

GORGONI, A. Amministrazione di sostegno e trattamenti sanitari. Europa e Diritto privato, Milão fasc. 2, p. 547-616, 2012.

INTRONA, F. Lo screening genetico ed il giudizio di idoneità al lavoro. Diritto e Società, Milão, p. 29, 1992.

LÓPEZ Y LÓPEZ, A. M. Fundamentos de derecho civil: doctrinas generales y bases constitucionales. Valencia: Tirant lo blanch, 2012.

MACILOTTI, M.; IZZO, U.; PASCUZZI, G.; BARBARESCHI, M. La disciplina giuridica delle biobanche. Pathologica, Milão, v. 100, p. 86101, 2008.

MACILOTTI, M. Consenso informato e biobanche di ricerca (Informed Consent and Research Biobanks). Nuova giurisprudenza civile commentata, Trento, v. 3, p. 153-165, 2009. 
MARTÍN ARRIBAS, C.; ARIAS DÍAZ, J. Biobancos y utilización de muestras de origen humano en investigación quirúrgica. Marco normativo actual. Cirugía Española, Madrid v. 89, n. 4, p. 207-212, 2011.

MOURE GONZÁLEZ, E. El consentimiento informado como derecho fundamental. Comentario a la Sentencia del Tribunal Constitucional 37/2011, de 28 de marzo. Diario La Ley, año XXXIII, Madrid, n.7912, Sección Doctrina, 2012

PARRA LUCÁN, M. A. La capacidad del paciente para prestar válido consentimiento informado. El confuso panorama legislativo español. Aranzadi Civil-Mercantil, Madrid, n. 2, p. 18-44, abr. 2003.

PICOZZI, M.; FERIOLI, E. La conservazione del materiale biologico finalizzato alla ricerca scientifica: questioni giuridiche e riflessioni etiche sulle biobanche. Medicina e Morale, Roma, v. 61, fasc. 4, p. 553-584, 2011.

REBOLLO DELGADO, L.; GÓMEZ SÁNCHEZ, Y. Biomedicina y protección de datos. Madrid: Dykinson, 2008.

ROMEO CASABONA, C. M. Utilización de muestras biológicas y bancos para la investigación biomédica. In: CONGRESO MUNDIAL DE BIOÉTICA. Ponencias y comunicaciones, Sociedad Internacional de Bioética, Gijón, 2005.

ROMEO CASABONA, C. M. Implicaciones jurídicas de la utilización de muestras biológicas humanas y biobancos en investigación científica. Bilbao, 2007 <http://www.catedraderechoygenomahumano. es/images/Informe_final_completo.pdf>. Acesso em: 25 abr. 2014

ROMERO PAREJA, A. Investigación biomédica responsable. Práctica de Derecho de Daños: Revista de Responsabilidad civil y seguros, Buenos Aires, n. 101, p. 8-24, 2012.

VILLANI, L. Biobanche e test rivelatori di informazioni genetiche: spunti di riflessione per un nuovo consenso informato. Responsabilità civile, Milão v. 7, p. 140-146, 2010. 
VILLANUEVA LUPIÓN, C. Autogobierno personal y discapacidad: la modificación judicial de la capacidad de obrar en la toma de decisiones. En: MUÑOZ, José Pérez de Vargas; VICENTE, Montserrat Pereña. La encrucijada de la incapacitación y la discapacidad. Madrid: La Ley, 2011. v. 2. p. 429-440.

VIVAS TESÓN, I. La dignidad de las personas con discapacidad: logros y retos jurídicos. Madrid: Difusión jurídica, 2010.

VIVAS TESÓN, I. Más allá de la capacidad de entender y querer: un análisis de la figura italiana de la administración de apoyo y una propuesta de reforma del sistema tuitivo español. Olivenza: Futuex, 2012 Disponivel em: <http://www.poderjudicial.es/cgpj/es/Temas/ Justicia-y-Discapacidad/Documentos-de-interes/Publicaciones/Masalla-de-la-capacidad-de-entender-y-querer----Un-analisis-de-la-figuraitaliana-de-la-administracion-de-apoyo-y-una-propuesta-de-reformadel-sistema-tuitivo-espanol>. Acesso em: 12 abr. 2016.

VIVAS TESÓN, I. Una propuesta de reforma del sistema tuitivo español: proteger sin incapacitar. RDP, Madrid, n. 5, p. 3-40, sep./oct. 2012.

Recebido em: 24/06/2015

Aprovado em: 24/11/2015 